\title{
Artigos
}

\author{
Alejandra Ciriza Jofré \\ CONICET, Argentina \\ IDEGE - Secretaría Académica - UNCuyo
}

\section{Genealogías feministas: sobre mujeres, revoluciones e llustración. Una mirada desde el sur}

\begin{abstract}
Resumen: Este trabajo apunta a la esbozar y reconstruir genealogías feministas desde el sur, procurando articular la reflexión filosófica sobre el pasado político de las mujeres y los fragmentos dispersos de la historia de las mujeres en Nuestra América. La lectura que me propongo realizar se halla ligada a una perspectiva sobre la relación entre pasado y presente vinculada a la inspiración benjaminiana. Desde ese punto de vista, el pasado que interesa a los y las subalternas es el tiempo ahora, esto es, un tiempo que se nutre del pasado, de la mirada hacia atrás, hacia ese momento significativo en la historia de Nuestra América - el de las guerras de independencia - y el presente. En aquel tiempo se abría un horizonte entonces anticipado como de inauguración de un nuevo tiempo y de un orden político nuevo. Esta reflexión está centrada en las relaciones entre cuerpo, política e historia desde un punto de vista que busca construir conocimiento situado, y producir una crítica a la tendencia a retornar sobre la idea del carácter a-histórico de la subordinación de las mujeres, a transformarla en lo que Geneviève Fraisse denomina una 'querella', un debate sin tiempo en el que se juega la eterna repetición de lo mismo. Una operación que, desde el punto de vista que sostengo, se duplica en el caso de las mujeres del sur. Palabras clave: genealogías feministas; pasado y presente; cuerpo y política.
\end{abstract}

Copyright @ 2012 by Revista Estudos Feministas.
Durante mucho tiempo me ha preocupado el modo como se reconstruyen las tradiciones teóricas y políticas de los sectores subalternos, en especial de las mujeres, el peso que ello tiene sobre las prácticas, sobre los procesos de legitimación de demandas, sobre los modos de significar su lugar y sus derechos en el espacio público.

Hacia inicios del siglo XX Gramsci había señalado que la historia de los sectores populares se presenta como discontinua y fragmentaria, un hilo frágil y escurridizo en la densa y consistente trama del relato que sobre sí construyen las clases dominantes. Gramsci dice exactamente:

La historia de los grupos sociales subalternos es necesariamente disgregada y episódica [...]. Los grupos 
' Antonio GRAMSCI, 1986, p. 493.

\begin{abstract}
2 Utilizo la noción de genealogía en el sentido de recuperación de la historia de nuestras antepasadas, de reconocimiento de los lazos que nos ligan con ellas, a sabiendas de que tal recuperación se produce a partir de un interés político y cognoscitivo ligado a la necesidad de historiza nuestra presencia en las luchas del pasado. Como he señalado en otros trabajos, la recuperación conlleva una labor de paciente recolección de lo disperso, a sabiendas de la provisoriedad de las junturas y de la tensión inherente a la tarea misma (Alejandra CIRIZA 2008).
\end{abstract}

\footnotetext{
${ }^{3}$ Existe una larga discusión acerca de la especificidad de las formas de dominación ejercidas sobre las mujeres a partir de la constitución del orden político moderno. Desde el punto de vista sostenido por Carole Pateman, el orden político moderno se construyó sobre la base de un contrato entre varones fraternos coligados que supuso, como paso previo, la derrota política de las mujeres, consideradas como políticamente irrelevantes (Carole PATEMAN, 1995).

${ }^{4}$ Walter BENJAMIN, 1982
}

subalternos sufren siempre la iniciativa de los grupos dominantes, incluso cuando se rebelan y se levantan. Incluso cuando parecen victoriosos los grupos subalternos se encuentran en una situación de alarma defensiva $[\ldots]{ }^{1}$

Sus tradiciones se olvidan, sus derechos son a menudo frágiles, sujetos a los avatares de victorias y derrotas. Tras los pasos de Gramsci pienso que la reconstrucción de las tradiciones políticas y las genealogías feministas tropieza con obstáculos semejantes. ${ }^{2}$ En el caso de las mujeres es imposible la reconstrucción de una historia, pues las mujeres son desiguales y diferentes entre sí, sus tradiciones políticas no son homogéneas, surcadas por desigualdades de clase, por el peso de las diferencias étnicas y culturales, por los énfasis diferenciales que producen las orientaciones sexuales, por los abismos de las lenguas y las ubicaciones geográficas.

A ello es preciso agregar la dificultad que produce el carácter supuestamente natural y a-histórico frecuentemente asignado a las consecuencias políticas de las diferencias entre los sexos, la persistencia de la neutralización de los cuerpos masculinos como aquellos aptos para el saber y la política, la despolitización de los asuntos que hacen a nuestros derechos.

De allí la importancia que asigno a la historia, pues las dificultades con las que tropieza la colocación de las demandas de mujeres y feministas en el espacio público remiten a la tenacidad de la asociación entre los cuerpos de las mujeres y la naturaleza, a la tendencia a borrar la historia de nuestra presencia en el espacio público y en los escenarios políticos, a deshistorizar y despolitizar los mecanismos políticos a través de los cuales se produjo, en los albores de la modernidad, la neutralización de los cuerpos masculinos, devenidos sin más los cuerpos de la política, la cultura, el saber, y se consideraron apolíticos los mecanismos a través de los cuales se aseguraba la reclusión doméstica de las mujeres, y su exclusión de todo debate relativo a la transformación del orden establecido. ${ }^{3}$

La lectura que me propongo realizar en este trabajo se halla ligada a una cierta perspectiva sobre la relación entre pasado y presente vinculada a la inspiración benjaminiana. ${ }^{4}$ El pasado que interesa a los y las subalternas es el tiempo ahora, esto es, ese tiempo que debe ser entendido en el sentido secular y colectivo de acción revolucionaria, un tiempo que se nutre del pasado, de la mirada hacia atrás, hacia ese momento significativo en la historia de Nuestra América en el que se abría un horizonte entonces anticipado como de inauguración de un nuevo tiempo y de un nuevo orden político, "el moderno régimen americano" en palabras del ecuatoriano Vicente Rocafuerte, que

614 Estudos Feministas, Florianópolis, 20(3): 613-633, setembro-dezembro/2012 
${ }^{5}$ La expresión es de Rocafuerte en su discurso A la Nación (Vicente ROCAFUERTE, 1908, p. 222).

\footnotetext{
${ }^{6}$ Existe una amplia bibliografía sobre las relaciones entre mujeres y revolución entre la cual vale la pena citar el clásico libro de Sheila Rowbotham, que recorre desde el siglo XVII, y el surgimiento de una sensibilidad milenarista afín a la emancipación de las mujeres pasando por la revolución francesa y la reacción napoleónica hasta las afinidades y tensiones entre marxismo y feminismo tanto en el nivel del pensamiento teórico como de las experiencias políticas de las revoluciones rusa y china (Sheila ROWBOTHAM 1976).
}

\footnotetext{
${ }^{7}$ CIRIZA, 2007.
}

establecería un tiempo de "libertad" y de "igualdad" tras el fragoso y difícil camino a transitar, una vez derrotado "el antiguo régimen español". ${ }^{5}$

De la promesa revolucionaria a la organización de los regímenes políicos nacidos del fragor de las guerras de independencia transcurrió un proceso que no precipitó en la emancipación soñada. ¿Qué abrió y cerró ese tiempo, cómo nos interpela aún, quiénes son, para las mujeres y feministas latinoamericanas, las antepasadas en las que reconocer nuestros deseos emancipatorios? ¿Cómo recuperar la complejidad de la presencia de las mujeres en una revolución de la que formaron parte, que culminó con la ruptura del lazo colonial clásico, pero que produjo, en orden a los derechos de las mujeres, pocos frutos efectivos? ¿Cómo entablar un diálogo con las/los feministas ilustradas/os que, en otras latitudes, forman parte de nuestras genealogías?

Desde mi punto de vista la operación de reconstrucción de genealogías feministas, o más modestamente, de mujeres, depende del desanudamiento de una serie de asuntos que, efectivamente imbricados entre sí en el orden de la historia, es preciso ubicar analíticamente sobre la base de una perspectiva que asume su carácter situado.

Las revoluciones de independencia abrieron espacios en los cuales, durante un tiempo fugaz, fueron posibles otras prácticas y relaciones desnaturalizadoras de la idea de que existen seres humanos inferiores por destino corporal. Sin embargo, esas transformaciones fueron posibles durante un tiempo breve en el que, por decirlo de alguna manera, una generación de varones y mujeres puso a la orden del día sus deseos de emancipación. La construcción del nuevo orden reubicaría a indios e indias, negros y negras y mujeres de todas las razas y clases sociales bajo relaciones de dominación cuyas formas, sin embargo, ya no serían las mismas. La difícil articulación entre los atributos reales de los sujetos y la igualdad jurídica como elemento fundacional del nuevo orden instauró una tensión compleja entre inclusión y exclusión, entre igualdad, desigualdad y diferencia. ${ }^{7}$

Si las revoluciones son esos momentos en que los y las condenados de la tierra sueñan con tomar el cielo por asalto, estas, nuestras revoluciones de independencia, se realizaron bajo el signo de la llustración.

Mujeres y revoluciones, mujeres e llustración, son asuntos ligados, pero es preciso un tratamiento parcialmente diferencial. Preguntarse qué hereda una de una revolución a 200 años de acontecida en un continente surcado por nuevas formas de dominación colonial exige una mirada atenta a la historicidad, vigilante ante la tentación de anulación de la historia en pura repetición de lo siempre 
${ }^{8}$ Fatima MERNISI, 2003.

igual. Preguntarse qué hereda una feminista latinoamericana de la llustración exige un esfuerzo teórico para saber qué es posible apropiarse bajo esta condición paradojal, pues la mirada desde el sur conlleva dificultades serias. Por alguna extraña razón, como señala Fátima Mernisi, las feministas occidentales

retienen el instinto distorsionador, racista e imperialista de los hombres occidentales. Incluso ante una mujer árabe (o latinoamericana, agregaría yo) con cualificaciones, conocimientos y experiencias similares a las suyas, ella(s) reproduce(n) inconscientemente los esquemas coloniales de supremacía. ${ }^{8}$

\section{Genealogías feministas, revoluciones, Ilustración}

"Existe una cita secreta entre las generaciones que fueron y la nuestra"

Walter BENJAMIN, 1982

Las memorias y genealogías feministas son un asunto complejo. Por una parte, porque el retorno hacia el pasado ofrece apenas senderos discontinuos, inacabados, trayectorias interrumpidas, documentos fragmentarios. Por la otra, porque las transformaciones en los escenarios políticos abren horizontes, iluminan procesos, movilizan hacia la búsqueda, e incluso el hurgueteo en un pasado que a menudo parece no pertenecernos. Incluso alumbran relaciones que antes no fueron siquiera consideradas.

La línea de reflexión que pretendo hilvanar, si bien dialoga con la seguida por otras investigadoras que, en otras latitudes, insisten sobre la historicidad de las demandas de las mujeres, indaga por la especificidad de las genealogías feministas desde el sur.

La cuestión de la historicidad suele tropezar de manera recurrente con el regreso de la querella como forma de significar el lugar de los reclamos de las mujeres y las feministas en la sociedad. Geneviève Fraisse ha señalado que el debate se presenta, al menos en Francia, bajo tres formas: la 'querella', que se produce durante los siglos XVII y XVIII, y está basada en una confrontación de argumentos fundados en el valor de los sexos. La pregunta sería ¿qué sexo es mejor? El 'proceso' en cambio se pone en marcha durante la Revolución Francesa, y hace referencia a una suerte de procedimiento jurídico por el cual se denuncia la desigualdad y se demanda igualdad, ante todo legal. Finalmente la 'controversia', que es el modo actual del debate, y está marcada por la incertidumbre respecto del acceso a la verdad y el reconocimiento de que se trata de

616 Estudos Feministas, Florianópolis, 20(3): 613-633, setembro-dezembro/2012 
9 Geneviève FRAISSE, 2001 a, $p$ 13-38; y FRAISSE, 2007, p. 43-56. una polémica inagotable en la cual no hay imparcialidad posible. ${ }^{9}$ El retorno de la querella obedece, según Fraisse, a que permite borrar la complejidad de las formas efectivas y determinadas de intervención de las mujeres en la historia, devolviendo la ilusión de una historia de mujeres habitada sólo por las excepciones que confirman la regla de un destino ahistórico, ligado a la pura biología, y por ello inmodificable.

El fantasma del bicentenario de las revoluciones de independencia recorre la América toda, no sólo porque se cumplen dos siglos del inicio de los procesos revolucionarios que culminaron con la ruptura del lazo colonial clásico, entre 1809 y 1824 , cuando el ejército español fue derrotado en Ayacucho, sino también porque un tiempo urgente parece cernirse sobre Nuestra América en esta coyuntura. Sin embargo, si es verdad que las revoluciones de independencia y sus protagonistas vuelven, invocados/as en forma expresa incluso en la denominación misma del proceso venezolano que se dice "bolivariano", recordadas/os en las efemérides escolares, traídos/as al presente desde las tensiones irresueltas y los dilemas que ese mismo proceso histórico dejara como herencia, también es verdad que ese retorno es menos simple de lo que podría creerse. Menos simple porque no se trata, para las feministas, de una genealogía que pueda indicarse como ligada a nuestras reivindicaciones. No eran feministas sino mujeres las que se batieron por la independencia del continente hace 200 años.

Si ese pasado común puede interpelar a subalternas y subalternos, es a la vez un pasado que nos es extraño, en alguna medida ajeno. Ajeno en el sentido de que el relato habitual apenas refiere, de manera indirecta y fugaz, a la presencia de indias/os negros/as y mujeres. No porque no los/las hubiera, sino porque la historia las/los ha olvidado. Lentamente ellas/os van ingresando en los relatos de la emancipación, ocupando un puesto en las narraciones, resquebrajando la ilusión de que la gigantesca tarea de la independencia fue obra de minorías criollas e ilustradas.

Por añadidura, las huellas de nuestras antepasadas latinoamericanas son apenas rastreables en archivos y repositorios documentales. Alguna carta de amor, correspondencia milagrosamente salvada de quemas y deterioros, designaciones como oficiales del ejército patriota en los casos paradigmáticos de Manuela Sáenz y Juana Azurduy, sentencias de ejecución contra las caudillas de tal o cual movimiento indio. ${ }^{10}$ Documentación escasa. Más bien acerca de ellas que "de" ellas. Manuela y Juana, Bartolina Sisa y Gregoria Apaza fueron hijas de la revolución, mujeres de acción, de la misma manera que lo eran muchas de las mujeres que recorrieron la América meridional al paso de las tropas indias en rebelión y de los ejércitos de independencia. 
"Las notables argumentaciones en defensa del derecho de las mujeres a la ciudadanía en los escritos de Condorcet, así como la conocida "Déclaration des droits de la femme et de la citoyenne", formaron parte de los debates sobre la constitución de orden político a fundar a partir de la conmoción generada por la Revolución Francesa. La Vindication fue escrita en 1792, en el contexto del florecimiento de ideas radicales en una Inglaterra donde el grupo de intelectuales al que Wolltonecraft pertenecía seguía apasionadamente el curso de la revolución francesa y ofrecía resistencia a los embates de los conservadores, que habían hallado un defensor de la tradición en Edmund Burke. El texto de Amar y Borbón, pronunciado en la Sociedad Económica de Amigos del País, en 1786, y titulado "Discurso en defensa del talento de las mugeres, y de su aptitud para el gobierno, y otros cargos en que se emplean los hombres se encuadra en un contexto menos turbulento, el del debate ilustrado sobre la educación de las mujeres como tema que articula la cuestión de las relaciones entre los sexos al debate sobre la moral, el matrimonio y el rol doméstico, moral e intelectual de las mujeres. ${ }^{12}$ La bibliografía sobre la independencia de las que fueron colonias españolas en América es vastísima. Es muy conocida la Historia de América Latina coordinada por Bethell, cuyos volúmenes 5 y 6 están destinados al proceso de emancipación y a la América independiente (Leslie BETHELL, 1991). Existen además dos valiosas selecciones de documentos editadas por Biblioteca Ayacucho: Haydée MIRANDA BASTIDAS y Hasdrúbal BECERRA, 2005; y Jose Luis ROMERO y Luis Alberto ROMERO, 1983.
El nudo que liga revolución e llustración, feminismo e llustración, parece más propicio para resistirse a la amnesia, pues su pertinencia para la recuperación de una genealogía feminista no ofrece ninguna duda. Sin embargo se trata, en todo caso, de genealogías extrañas y aún extranjeras, lejanas en el tiempo y en la lengua, aún cuando no en la preocupación por los derechos de las mujeres y la significación política de las diferencias entre los sexos: Olympe de Gouges, Nicolas de Condorcet, Mary Wollstonecraft, Josefa Amar y Borbón pusieron palabra al nudo complejo que liga llustración y feminismo hacia fines del siglo XVIII e inicios del XIX. La relación con su legado requiere de un procesamiento en una doble clave: por una parte, la de su indudable pertinencia, en la medida en que es preciso registrar la puesta a la orden del día del asunto de las consecuencias políticas de la diferencia entre los sexos como tema de reflexión teórica y política; por la otra, tal recuperación no puede hacerse por fuera de la historia, de las determinaciones efectivas que los procesos en los cuales estuvieron involucradas/o imprimieron a sus perspectivas sobre el lugar de las mujeres en el orden político, que de eso se trataba en los albores de la modernidad. ${ }^{11}$

\section{Revolución: indias, mestizas, criollas}

Hace 200 años, en 1809 y en diversos puntos del continente, la América entonces española iniciaba el ciclo de su emancipación en un marco internacional complejo y agitado: entonces, como ahora, estas tierras ocupaban la periferia colonial. ${ }^{12}$

Las tropas napoleónicas habían invadido España provocando en la península y en ultramar una reacción política que en España desencadenó lo que hoy se conoce como la Guerra de la Independencia Española y en las colonias un movimiento político múltiple, localizado en diversas latitudes de la entonces América española. El proceso de emancipación fue un proceso complejo, que hundía sus raíces en Europa, seguramente, pues de periferia colonial se trataba, pero también en estas tierras, conmovidas durante siglos por levantamientos indígenas ferozmente reprimidos, por fugas de negros a los espacios de libertad de los quilombos, por la circulación de libros prohibidos y por la organización de sociedades de amigos del país y también, desde 1789, por la impresión clandestina de la Declaración de los Derechos del Hombre y del Ciudadano. No sólo de criollos ilustrados se trataba. Dice Berta Wexler:

La intranquilidad social generada durante el siglo XVIII por el pago del tributo y la mita marcó un contexto de 
${ }^{13}$ WEXLER, 2008, p. 43.

rebeliones ocurridas en la sierra donde se desarrollaron los sectores económicos de la producción textil y la minera, que provocaron por diversas razones el descontento de la población indígena, mestiza y criolla. ${ }^{13}$

A la vez que las juntas apelaban al nombre de Fernando VII, el proceso incluía inquietudes relativas al mal gobierno, la difusión de ideas ilustradas, el descontento de las 'castas'. En el territorio grancolombiano había sido relevante la traducción, realizada en Bogotá por Antonio Nariño, de la Declaración de los Derechos del Hombre y del Ciudadano, el movimiento de Picornell y el conocimiento que de sus ideas tuvieron Gual y España. La protesta contra impuestos, estancos y alcabalas ocupaba un lugar relevante. En el Alto Perú se produjo, el 16 de julio de 1809, un levantamiento liderado por Pedro Murillo que dio lugar a la formación, el 27 de julio, de la Junta Tuitiva de los derechos del Rey, que redactó en La Paz una "Proclama en defensa de los derechos de los americanos". Ese mismo año hubo un levantamiento en Chuquisaca. Murillo fue ajusticiado en 1810, pero la guerra de republiquetas se instaló en el Alto Perú durante más de 15 años.

El 10 de agosto de 1809 tuvo lugar en Quito un alzamiento encabezado por el Marqués de Selva Alegre. Las autoridades españolas causaron la masacre del 2 de agosto de 1810. En mayo de 1810 se constituía en Buenos Aires la primera junta, y el 18 de septiembre del mismo año se organizaba una junta de gobierno en Chile. La mayor parte de los conatos revolucionarios provocaron brutales represalias. Desde entonces hasta 1824 un proceso de revolución y guerra recorrió la América meridional. Fue mucho más complejo de lo que una simple enumeración de acontecimientos dispersos en la geografía continental puede transmitir, y mucho más que lo que pueda sugerir el recuento de batallas, constituciones, proclamas, pacificaciones, enfrentamientos.

A menudo del relato de lo acontecido suele desprenderse que la independencia fue criolla, masculina y blanca. Las huellas de subalternos y subalternas se pierden en los meandros de la historia. La lectura habitual tiende a considerar el proceso emancipatorio de inicios del siglo XIX como una revolución desde arriba, promovida y azuzada por una minoría ilustrada que deseaba beneficiarse privadamente con la ruptura del lazo colonial clásico. Esa visión tiende a suprimir las tensiones e inflexiones del proceso y la diversidad de sujetos y experiencias en beneficio de una mirada que ve exclusivamente el resultado: la imposición de un nuevo orden con hegemonía criolla, que en realidad sólo logró establecerse una vez cerrado el ciclo 


\footnotetext{
14 Joaquín PEZUELA, 2008, p. 99.

${ }^{15}$ Fraisse ha señalado que la hipótesis de la historicidad de las consecuencias políticas de las diferencias entre los sexos es de difícil elaboración. La tentación de reenviar a la biología, el destino, o a una explicación esencialista las desigualdades entre varones y mujeres es recurrente (FRAISSE, 2001 a). La tendencia se agudiza cuando de mujeres no occidentales se trata. Chandra Mohanty ha ilustrado, en un conocido artículo, las formas distorsionadas bajo las cuales las teóricas occidentales conceptualizan las prácticas de las mujeres del tercer mundo (Chandra MOHANTY 1984, p. 51-80). Bell Hooks (2000, p. 44, traducción mía) no duda en señalar que: "Privileged-class white women swiftly declared their ownership of the movement, placing working-class white women, poor white women, and all women of color in the position of followers". Es decir: "Las mujeres blancas de clases privilegiadas se declaran rápidamente propietarias de movimiento, colocando a las mujeres blancas de clase trabajadora, a las mujeres blancas pobres y a todas las mujeres de color en la posición de seguidoras". Por lo que se refiere a Hegel, este afirma que "Lo que ahora acontece (en América) no es más que el eco del viejo mundo y reflejo de ajena vida" (Georg HEGEL, 1928, p. 186 t. 1).

${ }^{16}$ Asunción LAVRIN, 1985.
}

ascendente de la revolución, en 1824, después de Ayacucho.

Es difícil establecer qué papel les cupo a las mujeres, qué nexos hubo entre indios e indias sublevados/as y guerras de independencia, entre amazonas de la libertad continental y cacicas al mando de tropa, cuáles fueron sus formas de actuación, por cierto diversas. El general español Pezuela dice respecto del levantamiento de La Paz:

Esta infeliz y bárbara ciudad tuvo la nota de ser entre las demás la peor y más enérgica del Rey, de todos los Europeos y de los criollos fieles y honrados. Desde el 16 de julio de 1809 en que se sublevó [...] formando una junta con el nombre de Tuitiva [...]. Y dando al mestizo Pedro Murillo el mando militar fue la más acérrima defensora de la independencia; llegando a tal extremo que las mugeres tomaron el más colorado Partido, abandonaron la Religuión prostituyeron el pudor, y finalmente vivieron con el mayor desenfreno hasta $[. .$.$] que la recuperó el Exto. RI pacificador al$ mando del brigadier [...]. D. José Manuel Goyeneche. ${ }^{14}$

La dificultad con la periferia y con las formas como las latinoamericanas participamos de las revoluciones de la independencia consiste en que, en general, las lecturas autorizadas acerca de lo sucedido proceden del norte: si las intervenciones políticas de las mujeres sudamericanas no se ajustan a los modelos de acción o pensamiento acontecidos en el centro, sucede que, en el mejor estilo de Buffon, y su hipótesis acerca de leones calvos, hormigas gigantes y varones afeminados como pruebas irrefutables de la inferioridad de la vida en lo que los europeos de entonces consideraban "el nuevo mundo", los procesos históricos y sociales del continente americano (y peor aún si se trata de mujeres) son leídos como ecos tardíos y distorsionados, meros reflejos empobrecidos de vida ajena, por decirlo a la manera de Hegel. ${ }^{15}$

Según prominentes historiadoras norteamericanas y europeas, el ingreso a la modernidad política, marcado por el proceso de revolución y guerra que conmovió durante 20 años el continente (por tomar sólo el ciclo ascendente de la revolución, entre 1808 y 1824), nada cambió para nosotras, las mujeres del sur americano. Asunción Lavrin sostiene que la actuación de las mujeres en las guerras de emancipación no ha dejado otra huella que el recuerdo deshilvanado de algunos nombres ilustres, por cierto contraproducentes, desde su punto de vista, para la comprensión de la historia. ${ }^{16}$ Manuela Cañizares, para el Ecuador; Josefa Sánchez, esposa de José María España, para Venezuela; la espía colombiana, Policarpa Salvarrieta, la Pola, fusilada en 1817 como una de las principales 
agentes republicanas; María Sánchez de Thompson, la dama porteña del salón donde se entonó por primera vez el himno nacional argentino, Manuela Sáenz para la gran Colombia, las altoperuanas Vicenta Juaristi Eguino y Juana Azurduy, la chilena Javiera Carrera, no son sino 'heroínas' que conducirían a leer el proceso histórico en términos de excepción, y no mujeres con capacidad de actuación pública, muchas de las cuales se reconocían a sí mismas como ciudadanas, aún cuando fueran excepcionales. Como lo eran, por otra parte, la mayoría de las mujeres que participaron de las luchas políticas: Mary Woolstonecraft en Inglaterra, Judith Sargent-Murray en Estados Unidos, Olympe de Gouges, Manon Roland, Mme. de Condorcet en Francia. Para muchas historiadoras norteamericanas y europeas, si entre las aguerridas tropas insurgentes que lucharon durante más de 20 años contra un ejército regular bien armado, y fueron derrotadas, triunfaron o murieron en los campos de batalla, hubo miles de mujeres: las soldaderas, juanas, cholas o guarichas, mujeres de sectores populares, que acompañaban a los hombres a la guerra preparando la comida, cuidando a los enfermos y tomando ellas mismas las armas cuando era necesario, resistiendo al ejército realista, como las cochabambinas lo hicieron frente a las tropas de Goyeneche, lo sucedido en las colonias españolas no ocurrió del modo como ellas consideran que debió haber ocurrido. Es por esto que no tiene una significación emancipatoria para las mujeres.

Berta Wexler aporta como documento el relato del soldado Turpín al Gral. Manuel Belgrano sobre las mujeres de Cochabamba, escrito el 4 de agosto de 1812:

Al día siguiente hubo un embajador de parte de Goyeneche, previniendo que venían ellos a reunirse con sus hermanos, que desistan de esa empresa bárbara: el pliego se entregó al único oficial de caballería, don Jacinto Terrazas y habiendo éste preguntado a todas ellas si querían rendirse, dijeron que no, que más bien tendrían la gloria de morir matando y el embajador que vino de Cochabamba murió a manos de las mujeres. A poco rato se vio ya formado el ejército enemigo e inmediatamente rompieron el fuego las mujeres con los rebozos atados a la cintura, haciendo fuego por espacio

${ }^{17}$ WEXLER, 2008, p. $101 \mathrm{~s}$. de tres horas $[. ..] .^{17}$

Si nos ajustamos a la perspectiva de Lavrin, la defensa activa de la emancipación y la negativa a entregarse al ejército realista carecería de significado en relación con la emancipación y con la transformación de los papeles de las mujeres en la sociedad. La clave del proceso independentista habrían sido las ideas de la llustración. Los procesos revolucionarios nada transformaron. 
${ }^{18}$ La Historia de las mujeres dirigida por la/el notable historiador/a Georges Duby y Michelle Perro se titula precisamente Historia de las mujeres en Occidente. Un certero criterio reúne, en el volumen IV, sobre el siglo XIX escritos variados que incorporan consideraciones sobre las "Penélopes americanas".

${ }^{19}$ Es claro que 'occidente' se perfila por oposición a los/las otros/as no occidentales, es decir a todos/as aquellos/as que han sido sometidos/as a diversos procesos de dominación colonial. ${ }^{20}$ Véase Dominique GODINEAU, 2002, p. 25-44.
${ }^{21}$ Sentencia del tribunal realista, noviembre 1781. Documento publicado por WEXLER, 2008, $p$. 98, destacados míos.
La historiadora francesa Dominique Godineau indica que, mientras las norteamericanas (que ella, como gran parte de los europeos, denomina 'americanas' sin más) optan por una modalidad de intervención individual, a través de peticiones o cartas familiares, las francesas eligen tomar la palabra en público, escribir manifiestos, discursos o panfletos que en ningún caso están simplemente dirigidos a familiares, parientes y amigos. ${ }^{18}$ Queda flotando la interrogación acerca de las modalidades de intervención de las americanas del sur, toda vez que las autoras de esa Historia... entienden por 'americanas' a las mujeres blancas que entonces vivían en las 13 Colonias. Aún cuando los países del sur del Río Bravo formen parte de América, una regla no expresa hace que 'América' sea equivalente a una pequeña porción del continente: el territorio ocupado por las 13 Colonias inglesas. ${ }^{19}$ Los procesos acontecidos en las Colonias españolas no cuentan, aunque las guerras de independencia formaron parte del ciclo de las revoluciones burguesas del siglo XIX: sólo hubo, para una perspectiva llamativamente eurocéntrica, dos revoluciones: la Francesa y la llamada 'americana'. ${ }^{20}$

Lo cierto es que de las huellas discontinuas de las revolucionarias sudamericanas, indias y mestizas, protagonistas de los alzamientos de fines del siglo XVIII y de inicios del XIX, se pueden reconstruir con dificultad algunas vidas trágicas. La documentación es escasa. Aún así sabemos que Bartolina Sisa y Micaela Bastida compartieron la suerte de sus maridos en la rebelión y en la derrota: ambas fueron ejecutadas tras el fracaso de los levantamientos indios, ambas estuvieron al mando de tropas en tiempos de la rebelión. Conocemos la suerte de Gregoria Apaza, hermana de Túpac Katari, quien con Andrés Túpac Amaru presidió el tribunal de Sorata en el período insurreccional de la gran rebelión, entre 1780 y 1781 :

A Gregoria Apaza nominada execrablemente la reyna por Amada de Andrés Túpac Amaru y haberse sentado con éste a sentenciar el pueblo de Sorata en forma de Tribunal, la muerte de aquellos buenos y leales vasallos Españoles y blancos, que en número considerable fueron víctimas del furor bárbaro de estos carnizeros, sangrientos deshonestos y traidores. ${ }^{21}$

De las criollas tampoco se conservan demasiados documentos. Es sabido que Manuela Sáenz pesó lo suficiente en la vida política del Ecuador como para ser temida y expulsada por Rocafuerte. Después de Miñarica, el 14 de octubre de 1835 Rocafuerte, entonces presidente del Ecuador, le manifiesta a Flores su convencimiento de que "las señoras principales son enemigas declaradas de todo 
${ }^{22}$ ROCAFUERTE, 1988.

23 Mariquita SÁNCHEZ DE THOMPSON, 2003. orden". Encarnan el espíritu de la revolución y portan la capacidad de agitar la llama revolucionaria. En particular Manuela Sáenz, cuyo "carácter, talento, vicios, ambición y prostitución" no escapan a Rocafuerte. ${ }^{22}$ De allí la necesidad de expulsarla de territorio ecuatoriano hasta tanto la paz impuesta estuviera consolidada.

Entre los fragmentos dispersos del paso de las "ciudadanas americanas" por la política se halla la correspondencia que intercambiara con integrantes de su familia y con intelectuales de la época Mariquita Sánchez de Thompson, siempre interesada en los asuntos de la ciudad. ${ }^{23}$

La revolución y la guerra abrieron para las mujeres de la América meridional, de la misma manera que para las francesas, un espacio de actuación política y militar que les acarreó riesgos en el campo de batalla, exilios por razones políticas, pérdidas económicas y personales, persecuciones, prisión política, fusilamientos. Roto el lazo colonial la revolución arrojaría, en particular para ellas, escasos frutos. Quienes deseaban edificar el nuevo orden las percibían a menudo como una amenaza. Nada muy diferente, por otra parte, de lo que aconteciera en Francia después de la reacción termidoriana.

\section{Declinaciones ilustradas sobre cuerpo y política}

Los más radicalizados entre los ilustrados hispanoamericanos pensaban que de la conmoción social y política producida por el ciclo de revolucionario nacería un orden político, una transformación de las relaciones sociales guiada por la utopía de construir una sociedad de individuos libres e iguales, una sociedad emancipada del lastre de la tradición y la costumbre, independizada del lazo colonial que hasta ese momento había sujetado la suerte de los americanos a la servidumbre colonial respecto de la metrópolis española. En su Proclama a los indios del virreinato del Perú, señalaba Castelli:

Mi principal objeto es libertaros de su opresión, mejorar vuestra suerte, adelantar vuestros recursos, desterrar lejos de vosotros la miseria y haceros felices en vuestra patria. Para conseguir este fin tengo el apoyo de todas las provincias del Río de la Plata y sobre todo un exército superior en virtudes y valor a ese tropel de soldados mercenarios y cobardes con que intentan sofocar el clamor de vuestros derechos [... $]^{24}$

En los albores del ciclo revolucionario la apelación a la Ilustración y la repulsa de la tiranía ocupó un lugar importante para quienes propugnaban por la transformación 
${ }^{25}$ CASTELLI, $1811 \mathrm{~b}$. social a ambos lados del Atlántico. Castelli consideraba que el camino revolucionario iniciado era incompatible con la perpetuación del "sistema metropolitano". Decía "[...] sería un error contrario a los principios que sirven de base a nuestra constitución, y ya nuestro patriotismo sería un problema: más claro no haríamos más que imitar a los [...] tiranos que detestamos". ${ }^{25}$ El nuevo sistema de fraternidad se basaría en la equidad y la justicia, en el respeto por la ley y los derechos de los pueblos y los individuos, apartados los artificios y las tinieblas que fomentaban la ignorancia y el vasallaje.

Esos mismos principios de crítica a la tiranía y a las viejas astucias y engaños que mantienen la opresión de algunos y el privilegio de otros resuenan en las palabras de Mary Wollstonecraft. En la "Introducción" a su célebre Vindication, dice:

But if women are to be excluded, without having a voice from a participation of the natural Rights of mankind, prove first to ward off the charge of injustice and inconsistency that they want reason, else this flaw in your NEW CONSTITUTION will ever show that man must, in some shape, act like a tyrant, and tyranny, in whatever part of society it rears its brazen front, will ever undermine morality. ${ }^{26}$

La idea de que los regímenes políticos nacidos del ciclo de las revoluciones burguesas se organizarían a partir de un contrato por el cual el pueblo, un pueblo formado por individuos libres y formalmente iguales ante la ley, delegaría de manera transitoria la soberanía en sus representantes operó en un doble sentido. Por una parte instaló la idea de que la nueva sociedad estaría organizada en torno de los derechos individuales de los sujetos devenidos ciudadanos. El origen del poder había devenido humano. Por la otra, desmoronada la ciudadela del privilegio de nacimiento, una nueva luz irradiaba su resplandor igualitario sobre los sujetos subalternos, que adquirían el derecho a reclamar un lugar en un orden que se decía igualitario de manera expresa. La declaración de igualdad, por formal que ella fuera, tuvo efectos sobre la suerte de las mujeres y los/las sujetos subalternos.

La apelación a la igualdad fue, para ellos y ellas, una fuente de tensión, pues el 'nuevo régimen americano' no suprimió las formas de dominación patriarcal, las relaciones de servidumbre y explotación, el racismo y la convicción de la inferioridad de indio/as, negras/os, castas y mujeres. Sin embargo el tratamiento desigual ya no era considerado legítimo. La paradoja de la igualdad persigue desde entonces, como una pesadilla pertinaz, el sueño de dominación eterna y de perpetua desigualdad que suelen 
27 Véase AAW, 1996.

acunar los poderosos. Se había hecho visible que la exclusión de ciertos sujetos del goce de derechos y de la ciudadanía, ya fuera en razón de la propiedad, la raza, el sexo, no obedecía a la naturaleza de las cosas, sino a la existencia de relaciones de dominación que no reposan en derecho alguno, sino en el ejercicio de la fuerza y la violencia.

En lo que a las mujeres se refiere, la paradoja se perpetúa, pues si para algunos/as de la hipótesis de la igualdad de derechos de todos los seres humanos/as derivaba la idea de que la exclusión de las mujeres implicaba perpetuar en el nuevo orden elementos de la antigua tiranía, los cuerpos de las mujeres se han presentado en el imaginario político moderno como causa de desigualdad. Eliane Viennot, Jean Vogel y Claude Servan Schreiber indican que la idea moderna de la política implica el sueño de desligar política y corporalidad sexuada construyendo una forma de sociabilidad que permita la neutralización del sexo. ${ }^{27}$ De allí la asociación de las mujeres y sus cuerpos a la naturaleza, a fin de trazar para ellas un destino no sólo diferente, sino desigual. En los cuerpos de las mujeres se hallan las claves de un destino que las priva de la capacidad para transformar la sociedad y la historia de la que goza la otra mitad de la humanidad. Varones históricos y mujeres 'naturales' ocupan en la sociedad sitios dispares, pues en ellas habla la naturaleza y la materialidad del cuerpo sexuado, mientras en ellos, la cultura; en ellas, la familia, sujeta a los avatares de los ciclos biológicos de nacimiento, reproducción y muerte, en ellos, la sociedad.

Los varones ilustrados conjuraron del campo de la política el fantasma amenazante de la sexualidad humana excluyendo a las mujeres, construyendo un orden edificado sobre la abstracción de la corporalidad, una operación paradojal que procedió a la neutralización de las marcas sexuales de los cuerpos masculinos, considerados sin más como los cuerpos propios de la humanidad a través de la producción de la equivalencia entre hombre=varón $=$ ser humano. Las mujeres fueron y a menudo son aún consideradas como "el sexo".

La tensión entre quienes abogaban por el reconocimiento de derechos y quienes depositaban en las mujeres la función de únicos cuerpos verdaderamente sexuados se halla presente en los debates filosóficos y políticos que durante el siglo XVIII sostuvieron Rousseau y D'Alembert. En defensa del derecho de las mujeres a formar parte de la ciudad y a portar derechos ciudadanos argumentaron Condorcet, Olympe de Gouges y Mary Wollstonecraft, entre el/las más destacadas. Estas dos últimas y Condorcet abogaban, con argumentos diversos, por el derecho de las mujeres para ingresar en condición de ciudadanas como 
${ }^{28}$ Las fuentes relativas a este debate en Francia son por demás conocidas, y se hallan disponibles en el sitio de la Bibliothèque Nationale de France, Gallica. En español se encuentran la "Carta de D'Alembert a Jean Jacques Rousseau" (1759), traducida y publicada por Alicia Puleo. La compilación incluye una traducción del texto de Jean Antoine Nicolas Caritat de Condorcet, "Sur l'admission des femmes au droit de cité" "Sobre la admisión de las mujeres a derecho de ciudadanía"). El panorama se completa con uno de los textos más reconocidos: la célebre Declaración de los Derechos de la Mujer y la Ciudadana (1791) de Olympe de Gouges (PULEO, 1993). Recientemente han sido traducidos al español textos de Olympe de Gouges, Etta Palm, Théroigne de Méricourt y Claire Lacombe en una compilación titulada Cuatro mujeres de la Revolución Francesa (José BURUCÚA y Nicolás KWIATKOWSKI, 2007).

29 Jean Jacques ROUSSEAU, 2010.

${ }^{30}$ Marie Jean Antoine Nicolas de CONDORCET, 1847.

31 FRAISSE, 1995; y Bérengère MARQUES PEREIRA, 2004, p. 1621. parte del gobierno de la ciudad. ${ }^{28}$ Conforme a su posición, el ginebrino dibujó en el Emilio los destinos ejemplares del ciudadano Emilio y de Sofía, la mujer doméstica. ${ }^{29}$

La diferencia sexual, establecida por la naturaleza misma, marcaba un itinerario social predeterminado para las mujeres: maternidades, domesticidad, labores de aguja, una vida dedicada a lo que hoy llamaríamos el cuidado de otros y otras. Inhábiles para el saber, pero dotadas para el bordado, tan conveniente para una debida feminidad, las mujeres no serían jamás adultas en sentido estricto, pues eran incapaces de razonamientos teóricos y de elaborar juicios éticos con sentido universal. Por su parte, D’Alembert objetaba que la ferocidad de Rousseau contra las mujeres se asemejaba a la del vencedor respecto de los vencidos en alguna guerra. Condorcet, mientras tanto, señalaba que la marca de la diferencia sexual no es mucho más significativa que cualquier otra particularidad que los/las sujetos puedan portar. Si la menstruación fuera relevante en orden al ejercicio de los derechos ciudadanos, debería excluirse, también por razones biológicas, a todos aquellos que fueran propensos a indisposiciones transitorias, incluidos los resfríos, o a la gota. Ninguna marca corporal justifica, desde su perspectiva, hacer de las mujeres sujetos de tutela. Si ha sido posible privar de sus derechos naturales a la mitad de género humano, ello es sólo en virtud del poder del hábito, de la fuerza de la costumbre, que nubla incluso las mentes más esclarecidas. Tan racionales como los varones, las mujeres debieran gozar del derecho de ciudadanía. ${ }^{30}$

La filósofa inglesa Mary Wollstonecraft señalaba el dilema de los regímenes políticos modernos. Para ella, hacer de las diferencias entre los cuerpos sexuados de la humanidad una causa de subalternidad política era (y es) inaceptable, pues el principio que organiza los gobiernos modernos, la igualdad de los sujetos ante la ley, es incompatible con la preservación de cualquier tipo de privilegio. Excluir a las mujeres perpetúa el antiguo régimen en los cimientos del nuevo orden.

No por casualidad ese momento histórico, el de la coyuntura en la cual moría el antiguo régimen y se abrían las compuertas tumultuosas de la revolución, fue también un momento decisivo en el debate por los derechos de las mujeres a la educación y al voto, a ser consideradas como iguales. Así lo han señalado destacadas especialistas, filósofas, historiadoras, politólogas. ${ }^{31}$ ¿Por qué suponer que la suerte de las americanas del sur habría de ser diferente? Sólo el desplazamiento de la hipótesis de a-historicidad, esta vez sobre quienes agregan a su condición de género su lugar de habitantes de las colonias del sur americano, puede justificar semejante idea. 
${ }^{32}$ Véase Antoni DOMÈNECH, 2004 Sobre la familia Engels señala: "La palabra familia no significa en los orígenes el ideal del filisteo [...] hecho de sentimentalismo y escenas domésticas, ni siquiera se aplica [...] a la pareja y sus hijos, sino más bien a los esclavos. Famulus quiere decir esclavo doméstico y la familia son los esclavos que pertenecen a un mismo hombre. Familia es equivalente a patrimonio, es decir, la parte de la herencia legada por testamento [...] (el pater familiae) [que] tenía autoridad paternal romana sobre la mujer, los hijos y un cierto número de esclavos y tenía sobre todos ellos derecho de vida y de muerte" (Friedrich ENGELS, 1971, p. 67). Se pueden localizar versiones del texto de Engels en alemán, inglés y francés en <http://www. marxists.org/ archive/ $>$. Una edición reciente ha sido publicada en Buenos Aires por la editorial Luxemburg en 2007.

${ }^{33}$ Ricardo PALMA, 2007.
En el momento ascendente de la revolución se pensaba que era posible proceder a la demolición del antiguo régimen en múltiples niveles: destrucción de la loi politique que había sostenido el absolutismo monárquico, y en el caso hispanoamericano la expoliación colonial; efectuar el socavamiento del antiguo orden basado en el privilegio (la loi civile propia del ancien régime) para edificar una sociedad civil de nuevo cuño formada por individuos libres e iguales que habrían de acceder a la propiedad sobre la base del trabajo y el mérito, y transformar la loi de famille, que consideraba a los familiares como famulus, es decir, como sirvientes sujetos a la ley patriarcal. ${ }^{32}$ Tras la revolución y bajo el nuevo orden la familia continuó siendo un lugar de relaciones de dominación, y las mujeres continuaron siendo consideradas como extrañas al espacio político. Sin derechos, permanecieron durante siglos sujetas a la fuerza de una loi de famille restaurada, producto de los aires que recorrieron Europa tras el directorio y el imperio. El Código de Napoleón colocó a las damas en el debido lugar: el salón, la cocina, la caballerosidad y la tutela. No sólo a las francesas, pues fue adoptado por la mayor parte de los nacientes estados nacionales y replicado en los ordenamientos jurídicos internos en toda América Latina.

Hacia fines del siglo XIX, calmada la agitación social y finalizado el proceso revolucionario, Ricardo Palma desgrana en uno de los artículos publicados en la séptima serie de Tradiciones peruanas, un relato sobre "Ia protectora y la libertadora" que ilustra el borramiento de la historicidad, el retorno de la querella, que desea ver en los destinos de las mujeres la realización presunta de algún designio de la biología.

Yo que tuve la buena suerte de conocer y tratar a la favorita de San Martín y a la favorita de Bolívar, puedo establecer cardinales diferencias entre ambas. Física y moralmente eran tipos contrapuestos. En la Campusano vi a la mujer con toda la delicadeza de sentimientos y debilidades propias de su sexo. En el corazón de Rosa había un depósito de lágrimas y de afectos tiernos, y Dios le concedió hasta el goce de la maternidad, que negó a la Sáenz. Doña Manuela era una equivocación de la naturaleza, que en formas esculturalmente femeninas encarnó espíritu y aspiraciones varoniles. No sabía llorar, sino encolerizarse como los hombres de carácter duro. ${ }^{33}$

Si Rosita Campusano podría haber sido considerada como la "Sofía" de San Martín, Manuela encarnaba el fantasma temido de las mujeres con derechos y vocación política: un error de la naturaleza, y no una hija de su tiempo, una mujer política que había comprendido con claridad la 
hora que le tocara vivir, con las armas en la mano, como por otra parte lo habían hecho muchos varones y miles de mujeres anónimas.

\section{Consideraciones finales. De revoluciones y herencias ilustradas. Apropiarse la herencia política de la Ilustración}

La memoria de las guerras de independencia y de la significación emancipatoria que el proceso revolucionario pueda haber tenido resulta de difícil recuperación en el presente. Dificultad ligada, por una parte, al carácter fragmentario que tiene la historia de subalternos $y$ subalternas, a lo que se suma la dificultad inherente a lo que Geneviève Fraisse denomina "la hipótesis de la historicidad" de las consecuencias políticas de las diferencias entre los sexos.

Si la reconstrucción histórica del lugar de las mujeres en las luchas políticas del pasado resulta complicada en los países centrales, donde existen políticas de preservación de documentos y es posible desarrollar la pasión por los archivos, tal recuperación es mucho más difícil en nuestros países, donde archivos y papeles suelen estar sujetos a destinos azarosos, a políticas discontinuas. Y ello no sólo vale para las muchas anónimas que se sumaron a las guerras de independencia, indias, negras, mestizas, sino incluso para Manuela Sáenz, muerta a causa de una epidemia de difteria en 1856, por lo cual todas sus posesiones fueron incineradas, incluidas las cartas para $y$ de Bolívar, y documentos de la Gran Colombia que mantenía bajo custodia.

Sin lugar a dudas es preciso considerar esa dificultad, pero a ella se suma la cuestión de la recurrencia de la concepción de la política como un espacio destinado a ciudadanos abstractos, incorpóreos, aún cuando sus cuerpos no sean en modo alguno neutrales, sino sexuados, masculinos. El peso de esta tradición ubica a las mujeres en los únicos sitios posibles para ellas: compañeras-madresamantes de ciudadanos, del mismo modo que Sofía y Emilio, o Rosita Campuzano y el general San Martín.

Al peso de estas tradiciones teóricas y políticas que naturalizan para las mujeres el destino doméstico y eternizan la loi de famille es preciso sumar el desplazamiento que a menudo los modelos eurocéntricos producen. Si es verdad que la loi de famille ha conservado formas patriarcales en la América del sur, ello se debe a una serie de elementos históricos, políticos y sociales a cuya especificidad y espesor histórico es preciso atender. Ello sin descuidar la necesidad de una posición crítica que nos ubique frente a nuestra 
${ }^{34}$ Luigi FERRAJOLI, 1999, p. 82. propia historia a sabiendas de que, discontinuas como son, las tradiciones revolucionarias hallan dificultades para la transmisión.

En cuanto a la llustración, ella es menos unidimensional de lo que a menudo se pretende. De la misma manera que las herencias revolucionarias nada aseguran en relación al lugar de las mujeres, la llustración ha dejado una herencia desigual. Si Rousseau continúa siendo la fuente recurrente de una línea argumentativa que equipara a las mujeres a la naturaleza y a los varones a la cultura, muchos de los llustrados sostuvieron una idea normativa de igualdad.

Geneviève Fraisse y Luigi Ferrajoli han argumentado, desde mi punto de vista, en la dirección adecuada. La igualdad no es un hecho, sino un valor, no una aserción, sino una prescripción que implica reconocer descriptivamente que los seres humanos son diversos. Si no hay ningún ser neutro, si no hay el Hombre, sino seres humanos normativamente iguales, y ontológicamente diversos, el derecho a la igualdad que, por decirlo a la manera de Ferrajoli, "no será nunca otra cosa que la idéntica titularidad y garantía de los mismos derechos fundamentales independientemente del hecho, incluso por el hecho de que los titulares son entre sí diferentes". ${ }^{34}$

Esta es, sin duda, la herencia más preciosa de la llustración, una herencia universalmente compartida que halló portavoces en tierras americanas, mujeres y varones que pagaron, muchas veces muy caros, sus deseos de libertad, igualdad, fraternidad. En el fragor de aquellas batallas, y al calor de sus derrotas, los sueños de fueron agostando, las formas de dominación rehicieron su trama. Pero, es preciso decirlo, la suerte no estaba ni está echada de antemano. Nada hay en la historia que condene de antemano, ninguna naturaleza ni destino que sujete a las mujeres a la suerte rousseauniana. Sí la tentación recurrente de transformar la historia en eterna querella, es decir, en una historia que no se juega como tal, sino como destino preestablecido. Probablemente mucho más si se trata de mujeres, y aún más si esas mujeres habitan la periferia. De allí la relevancia del gesto político de apropiación de una herencia teórica y política feminista que no procede de ninguna continuidad ligada a la biología, sino de la voluntad teórica y política de hallar en ella, una y otra vez, las razones renovadas para nuestras utopías políticas de libertad, igualdad, fraternidad. 


\section{Referencias}

AAV. Projets Féministes, Actualité de la Parité. Séminaire à neuf rencontres introduit et animé par Marie Victoire Louis, avec Geneviève Fraisse, Francoise Gaspard, Danielle Haase - Dubosc, Claude Servan Schreiber, Mariette Sineau, Gisèle Stievenard, Eliane Viennot, Jean Vogel, etc. Paris, février 1996. n. 4/5.

AMAR Y BORBÓN, Josefa. "Discurso en defensa del talento de las mugeres, y de su aptitud para el gobierno, y otros cargos en que se emplean los hombres". In: GÓMEZMARTíNEZ, José Luis (Ed.). Antología del ensayo ibero e iberoamericano. 1786. Disponible en: <http://www.fhaugsburg.de/ harsch/hispanica/Cronologia/siglo18/ Amar/ama_intr.htm>. Acceso en: 10 nov. 2011.

BENJAMIN, Walter. "Tesis de filosofía de la historia". In: Para una crítica de la violencia. México: La nave de los locos, 1982. p. 99-132.

BETHELL, Leslie. Historia de América Latina. Barcelona: Crítica, 1991. v. $5 / 6$

BURUCÚA, José; KWIATKOWSKI, Nicolás. Cuatro mujeres de la Revolución Francesa: Olympe de Gouges, Etta Palm, Théroigne de Méricourt, Claire Lacombe. Estudio preliminar de José Sazbón. Buenos Aires: Biblos, 2007.

CASTELLI, Juan José. El Excmo. Señor Representante de la Junta Provisional Gubernativa del Rio de la Plata. A los indios del vireynato del Perú, 5 de febrero de 1811. Buenos Ayres: Real Imprenta de Niños Expósitos, 1811 a. Publicado por La Revolución de Mayo a través de los impresos de la época, Primera Serie 1809-1815, Tomo I, 1809-1811. Buenos Aires: Comisión Nacional Ejecutiva del 150 Aniversario de la Revolución de Mayo 1965. p. 425-428.

Manifiesto. Que dirije á los pueblos interiores del virreynato del Perú al Excmo. Sr. Dr. D. Juan José Castelli, abril de 1811. Buenos Ayres: Imprenta de Niños Expósitos, $1811 \mathrm{~b}$. Versión extraída de la Biblioteca de Mayo. Sumarios y expedientes. Tomo XIII. Buenos Aires: Senado de la Nación, 1962. p. 11497-11500.

CIRIZA, Alejandra. "La formación de la conciencia social y política de las mujeres en el siglo XIX latinoamericano: mujeres, política y revolución: Juana Azurduy y Manuela Sáenz". In: ROIG, Arturo (Comp.). El pensamiento socialy político iberoamericano del siglo XIX. Madrid: Trotta, 2000. p. 143-168.

"Ciudadanía de mujeres". In: GAMBA, Susana (Coord.). Diccionario de estudios de género y feminismos. Buenos Aires: Biblos, 2007. p. 55-57. 
- "Genealogías feministas y memoria: a propósito de la cuestión de la ciudadanía de mujeres". In: Intervenciones sobre ciudadanía de mujeres, política y memoria. Perspectivas subalternas. Buenos Aires: Feminaria Editora, 2008. p. 25-57.

CONDORCET, Marie Jean Antoine Nicolas de. "Sur l'admission des femmes aux droits de cité". In: Oeuvres de Condorcet. Paris: Firmin Didot, 1847. p. 121-130. v. X.

DOMÈNECH, Antoni. El eclipse de la fraternidad. Barcelona: Crítica, 2004.

DUBY, Georges; PERROT, Michelle. Histoire des femmes en Occident. Paris: Perrin, 2002. 5 v.

ENGELS, Friedrich. El origen de la familia, la propiedad privada y el Estado. 9. ed. Buenos Aires: Claridad, 1971.

FERRAJOLI, Luigi. Derechos y garantías: la ley del más débil. Madrid: Trotta, 1999.

FRAISSE, Geneviève. Muse de la raison. Paris: Gallimard, 1995. . "La différence des sexes, une différence historique". In: Dans: la controverse des sexes. Paris: PUF, 2001a. p. 13-38

"Soeurs et frères". In: sexes. Paris: PUF, 2001b. p. 45-64.

"A distancia del género". Estudios de Filosofía Práctica e Historia de las Ideas, año 8, n. 9, p. 43-56, dic. 2007.

GODINEAU, Dominique. "Filles de la liberté et citoyennes révolutionnaires". Histoire des femmes en Occident. Paris: Perrin, 2002. p. 25-44. v. IV.

GOUGES, Olympe de. "Déclaration des droits de la femme et de la citoyenne". In: PELLERIN, Nicole (Apres.). Écrits féministes. Paris: Flammarion, 2010. p. 78-93.

GRAMSCI, Antonio. "Apuntes sobre la historia de las clases subalternas: criterios metodológicos". In: SACRISTÁN, Manuel (Selec.). Antología. 9. ed. México/Madrid/Bogotá: Siglo XXI, 1986. p. 491-494.

HEGEL, Georg. Lecciones sobre la filosofía de la historia universal. Madrid: Revista de Occidente, 1928.

HOOKS, Bell. Feminism is for Everybody: Passionate Politic. Cambridge: South End Press, 2000.

LAVRIN, Asunción (Comp.). Las mujeres latinoamericanas: perspectivas históricas. México: FCE, 1985.

MARQUES PEREIRA, Bérengère. "Citoyenneté". In: HIRATA Helena et al. (Cord.). Dictionnaire critique du féminisme. Paris: PUF, 2004. p. 16-21.

MARXISTS INTERNET ARCHIVE LIBRARY. Disponible en: < http:// www.marxists.org/archive> Acceso en: 10 nov. 2011.

MERNISI, Fatima. Sobre la autonomía del feminismo árabe. Disponible en: <http://www.mundoarabe.org/ mujer_musulmana.htm>. Acceso en: 10 nov. 2011. 
MIRANDA BASTIDAS, Haydée; BECERRA, Hasdrúbal. La Independencia de Hispanoamérica, Declaraciones y Actas de Independencia. Caracas: Ayacucho, 2005.

MOHANTY, Chandra. "Under Western Eyes." In: MOHANTY, Chandra; RUSSO, Ann; TORRES, Lourdes. Third World Women and the Politics of Feminism. Bloomington: Indiana University Press, 1984. p. 51-80.

PALMA, Ricardo. La protectora y la libertadora. 2007. Disponible en: <http://es.wikisource.org/wiki/ La_Protectora_y_la_Libertadora>. Acceso en: 10 nov. $20 \overline{1} 1$.

PATEMAN, Carole. El contrato sexual. Barcelona: Anthropos, 1995.

PEZUELA, Joaquín. "Memoria militar, 1813-1815". In: WEXLER, Berta. Juana Azurduy y las mujeres de la revolución altoperuana (1809-1825). Rosario: Propuesta Gráfica, 2008. p. 99.

PULEO, Alicia. La ilustración olvidada: la polémica de los sexos en el siglo XVIII. Barcelona: Anthropos, 1993.

ROCAFUERTE, Vicente. A la Nación. Quito: Tipografía de la Escuela de Artes y Oficios, 1908.

. "Carta a Juan J. Flores, 14 de octubre de 1835". In: . Epistolario. Quito: Banco Central del Ecuador, 1988. v. 2.

ROMERO José Luis; ROMERO, Luis Alberto. Pensamiento político de la Emancipación (1790-1825). Caracas: Ayacucho, 1983. 2 v.

ROUSSEAU, Jean Jacques. Émile ou De l'éducation. Paris: Flammarion, 2010.

ROWBOTHAM, Sheila. Donne, resistenza e rivoluzione: una analisi storica per una discusione attuale. 2. ed. Torino: Giulio Einaudi, 1976.

SÁNCHEZ DE THOMPSON, Mariquita. Intimidad y política: diario, cartas y recuerdos. Buenos Aires: Adriana Hidalgo, 2003.

WEXLER, Berta. Juana Azurduy y las mujeres de la revolución altoperuana (1809-1825). Rosario: Propuesta Gráfica, 2008.

WOLLSTONECRAFT, Mary. "A Vindication of the Rights of Woman". In: TODD, Janet (Ed.). Political Writings. Toronto: University of Toronto Press, 1993. p. 67-296.

[Recebido em 17 de setembro de 2011 e aceito para publicação em 16 de dezembro de 2011] 


\section{Feminist Genealogies: On Women, Revolution \& Enlightment. A Point of View from the} South

Abstract: The goal of this work is to sketch and reconstruct Feminist Genealogies from a southern perspective. It aims to articulate a philosophical reflection on women's political past and the disperse fragments of the history of women (herstory) in Our America. This reading will be based on the Benjaminian thought about the relationship between past and present. From this point of view, the past that concerns subalterns is the jetzt zeit, a present time that is fed from the regard to the past. Namely, in this case, the relationship between a significant time of the History of Our America - the time of the Independence Wars during the nineteen century - and the present. At the time new horizons were opened, then anticipated as the inauguration of a new time and a new political order. This reflection is focused on the relationship between body, politics and History/Herstory with the attempt to build situated and critical knowledge against the idea of the a-historical character of subordination of women, to transform it into what Genevieve Fraisse called a "querelle", that is a timeless debate in which the endless repetition of the same situation is at play. In this note we will discuss how and why this operation multiplies in the case of the southern women.

Key Words: Feminist Genealogies; Past and Present; Body and Politics. 